\title{
SÉCULO XX: PRESENTISMO, GUERRA E CINEMA
}

TWENTIETH CENTURY: PRESENTISM, WAR AND CINEMA

João Leopoldo e Silva ${ }^{1}$

Resumo: O presente texto busca relacionar o conceito de presentismo, apresentado e desenvolvido por François Hartog, e sua relação com cinema e guerra. Para tanto serão analisadas duas cenas do filme Full Metal Jacket (Nascido para matar, 1987), dirigido pelo aclamado diretor norte-americano Stanley Kubrick.

Palavras-chave: Presentismo, Guerra, Cinema.

Abstract: This text seeks to relate the concept of presentism, presented and developed by François Hartog, and its relationship with cinema and war. For this purpose it will be reviewed two scenes from the movie Full Metal Jacket (1987), directed by acclaimed US director Stanley Kubrick.

Key-words: Presentism, War, Cinema.

Desde os primórdios do cinema, diferentes pesquisadores se esforçam para compreender como os filmes expressam muitas das angustias e expectativas presentes na história contemporânea. A importância do cinema deve-se não somente ao fato dele ser uma inovação tecnológica revolucionária, mas também por expressar anseios e desejos do momento de sua produção. Grandes pesquisadores (hoje clássicos), como Marc Ferro, Siegfried Kracauer e David Bordwell servem como base para o entendimento analítico de vários filmes. Diversos historia-

\footnotetext{
${ }^{1}$ Graduando em História pela PUC-SP.
} 
dores brasileiros fizeram seu percurso acadêmico voltado ao desenvolvimento de um ramo historiografico que procurasse relacionar História e Cinema, analisando, assim, métodos de aproximação entre as duas áreas.

Além da discussão teórica e metodológica destes autores, o cinema pode ser analisando perante outra ótica: a partir da teoria dos Regimes de Historicidade, mais especificamente sobre a ótica do presentismo que o historiador francês François Hartog desenvolve em seu estudo. O entendimento desta teoria é essencial para a realização da análise do filme Full Metal Jacket (1987).

Podemos definir à grosso modo como os Regimes de Historicidade sendo as maneiras nas quais as sociedades ao longo do tempo se relacionaram perante ele; já o presentismo é o nome dado à relação que nós, como sociedade contemporânea (pós-1789 e 1989), temos com o Tempo. Esta relação se da primordialmente a partir do tempo Presente, na qual a acelaração das comunicações e avanços tecnológicos que visam atingir o tempo do 'instantâneo' fazem parte. Porém, antes de iniciarmos o estudo dos Regimes de Historicidade, é importante ressaltar a relação entre autor, objeto de estudo e época em que seu livro é escrito.

Afim de compreender de que maneira chegamos a ter esta relação com Tempo, Hartog se desloca para o momento histórico da Revolução Francesa, focalizando um personagem histórico chamado Chateubriand (nascido em 1768), um "homem que nadou entre duas margens do tempo" (Hartog, 2014: 247). Chateubriand viveu na transição entre dois Regimes de Historicidade: a passagem do Antigo Regime para o Mo- 
derno, onde um novo mundo, pós-Revolução Francesa (simbolizada em 1789), se inicia. Chateubriand não permanece muito tempo nesta nova França e parte para a América, lugar no qual ele encontra dois tipos de liberdade: do selvagem e do Estado Moderno americano.

"Propondo um princípio de historicização (a liberdade filha das luzes sucedendo àquela que é filha dos costumes), ele vê os Estados Unidos não somente como a terra da invenção da nova liberdade, mas também como o laboratório onde se efetuou "quase sem esforço e rapidamente, a passagem de uma à outra" (Hartog, 2014: 118).

Hartog busca nas reflexões de Tocqueville e de Volney, outros dois viajantes, um complemento às ideias de Chateubriand. Os três "sabiam, cada um de seu modo, que o antigo regime de historicidade, tanto pelo tempo sustentado pelo modelo de historia magistra, não era mais operatório. A intelegibilidade do que acontecia implicava articular de outra maneira as categorias do passado e do futuro" (Hartog, 2014: 131). Enxergam que o Novo Mundo, a América, não é mais "conservatório ou utopia passadista, ela é doravante o cadinho onde se forja o futuro. O Novo Mundo dos descobridores tornou-se o mundo novo, aquele da igualdade, na direção do qual o Antigo Mundo marcha mais lentamente e com dificuldade" (Hartog, 2014: 131). O nascimento, portanto, de uma nova ciência política não vem de inspirações do passado, mas do futuro: é nele que a liberdade se encontra.

Apesar de poucos anos separarem os dois regimes (o Antigo do Moderno), notamos uma clara ruptura e mudança entre eles. Em território francês, devastado por uma violenta guerra civil, foi necessário além 
da construção do 'novo', a reconstrução do que havia sido destruído. Aqui as duas palavras, construção e reconstrução, têm duplo sentido: político e físico. Político no momento em que novas dicussões e novos modelos de Estado são instaurados, e físico no âmbio da reconstrução e resignificação de prédios e símbolos franceses.

Mesmo que contemporânea umas das outras, cada sociedade possui uma relação diferente com o tempo. Suas experiências históricas as caracterizam particularmente. Porém, quando falamos de momentos históricos mais tensos e dramáticos, como por exemplo uma guerra entre duas (ou mais) nações, cada uma delas terá uma relação particular com este acontecimento: os vencedores terão uma percepção deste tempo diferente dos vencidos. Isso vale não apenas para a historiografia mas para os Regimes de Historicidade: a relação com o passado, com o presente e até mesmo com o futuro difere na maneira como cada sociedade enfrenta seus desafios e avança os anos.

Hartog, ao se aproximar dos séculos XX e XXI, identifica uma crescente preocupação com a Memória e com a Preservação - escritas aqui com letra maiúscula pois são, além de palavras, conceitos. Ambas estão diretamente ligadas com o tempo do futuro que, progressivamente, passou de um lugar utópico, glorioso, para o lugar da incerteza, da insegurança e do pessimismo. Lembrar e preservar hoje, por quê? Há um risco iminente de destruição? De perda? Este risco é certo ou é apenas especulação?

"O século XX aliou, finalmente, futurismo e presentismo. Se, em primeiro lugar, ele foi mais futurista do que presentista, terminou 
mais presentista que futurista. Foi futurista com paixão, com cegueira até o pior, hoje todos sabem. Futurismo deve ser entendido aqui como a dominação do ponto de vista do futuro. Este é o sentido imperativo da ordem do tempo: uma ordem que continua acelerando ou se apresentando como tal" (Hartog, 2014: 141).

O presentismo, segundo Hartog, se apresenta como a dilatação do tempo presente, na qual a necessidade e a urgência do 'iminente' acaba por sobrepor o futuro: ele precisa acontecer agora. A própria criação de um novo tipo de historigrafia, iniciada por Marc Bloch e Lucien Febvre, dos Annales, representa um novo regime de historicidade: "o trabalho do historiador sob o signo de um duplo movimento: do passado para o presente e do presente para o passado" (Hartog, 2014: 145). Podemos pensar também sobre as produções cinematográficas, elas não deixam de ser fruto de seu tempo, mas visam retratar e/ou buscar um tempo passado. O filme Full Metal Jacket, por exemplo, apesar de ser produzido em 1987, doze anos após o término da Guerra do Vietnã (1955 1975), possui um potencial muito grande ao analisarmos o contexto geral da Guerra Fria: um filme que retrada um momento histórico muito próximo ao seu, inclusive de uma certa maneira o mesmo período.

Afim de entender o filme em seu contexto histórico, é preciso ir ao encontro das 'mentalidades' e experiências de ambos os momentos: da narrativa e da sua produção. Um grande historiador brasileiro, Nicolau Sevcenko, buscou compreender este momento, que foi muito influênciado pelo conturbado início do século XX. Em dois importantes tra- 
balhos $^{2}$ para o estudo, Sevcenko apresenta (e representa) uma visão sobre a história ocidental entre o fim do século XIX e o começo do século XXI, procurando ponderar não apenas fatos históricos, mas abranger diversas áreas do conhecimento, enxergando nas artes plásticas sua expressão. A metáfora da montanha-russa, apesar de causar um certo estranhamento em um primeiro momento, é extremamente forte para demonstrar a relação entre 'progresso e desenvolvimento', 'progresso, velocidade e tempo'.

É importante notar que a vertigem que vivemos no século XXI, proveniente da metáfora do loop (da montanha russa), é identificada por Hartog como crise do presentismo. Ambos os autores enxergam o tempo como uma problemática importante que não se limita a historiografia mas atinge nossa maneira de nos relacionar com o tempo (inclusive o do relógio) e como ele influencia o imaginário coletivo (e vice-versa). Inclusive o próprio título de um capítulo escrito por Sevcenko, $O$ vento das trincheiras ainda é quente, demonstra que o período da guerra de trincheiras da Primeira Guerra Mundial ainda não passou: os horrores que aconteceram lá ainda estão, de certa maneira, vivos e latentes, influênciaram o andamento do século XX como um todo, e ainda continua a nos influenciar.

\footnotetext{
${ }^{2}$ SEVCENKO, Nicolau. A corrida para o século XXI: no loop da montanharussa. São Paulo: Companhia das Letras, 2001; e SEVCENKO, Nicolau. Orfeu exático na metrópole - São Paulo, sociedade e cultura nos frementes anos 20.
} São Paulo: Companhia das Letras, 1992. P. 153-201. 
Para chegar a esta conclusão, Sevcenko encontra no fim do século XIX e início do XX (1870 - 1914), na chamada "paz armada", o começo do processo de aceleração do tempo. Ele se dá principalmente pela corrida armamentista e tecnológica que países europeus (lê-se Alemanha, França, Inglaterra e Rússia, principalmente) passaram afim de exercer seu controle sobre outras nações mais fracas (imperialismos) e para, "eventualmente", se proteger dos outros corredores.

"Por trás dessa vertigem coletiva da ação e da velocidade, engedrando-a, estimulando-a, sem permitir a reflexão sobre suas consequiências nas mentes e na cultura, as inovações tecnológicas invadiam o cotidiano num surto inédito, multiplicando-se mais rapidamente do que as pessoas pudessem se adaptar a elas e corroendo os últimos resquícios de um mundo estável e um curso de vida que as novas gerações pudessem modelar pelas antigas. As novas formas de energia ampliavam o tempo sem parar, na proporção inversa em que encurtavam os espaços. A matéria passava a obedecer cegamente a essas fontes invisíveis de energia e tudo parecia instável, a se mover, até as estruturas de aço maciço da Torre Eiffel subindo aos céus, ou as seculares muralhas de Viena desaparecendo da noite para o dia, para dar lugares a novas avenidas cheias de veículos velozes e palácios modernos erguidos num piscar de olhos" (Sevcenko, 1992: 162)

O próprio conceito de "eficiência", de "produtividade" e de "eficácia" são fatores provenientes e influenciadores neste novo mundo inaugurado pelo mundo pós-guerra. O tempo acelerado exige meios e modos mais rápidos de produção ${ }^{3}$. Um mundo mais produtivo é um mundo adaptado ao homem e a máquina, se é que ainda são diferentes um do outro. Não podemos deixar de lado as tendencias artísticas surgi-

\footnotetext{
${ }^{3}$ A este aspecto a bibliografia é vasta. Ver, por exemplo, Paul Virilio, Guerra Pura, de 1983.
} 
das na Alemanha durante a República de Weimar (1919 - 1930). O movimento artístico chamado New Objectivity ${ }^{4}$, nos quais artistas como Otto Dix (1891 - 1969) e George Grosz (1893 - 1959) participaram, demonstraram a sua maneira, a 'decadência' da sociedade alemã do pósguerra e a fusão entre homem e máquina. Um quadro titulado Dance of Death $1917^{5}$, de Otto Dix, é um exemplo privilegiado de arte feita por um ex-soldado e combatente das trincheiras.

Entre os anos de 1918 e 1939 um novo período de paz se instaurou na Europa. Uma paz contudo bastante conturbada. Apesar da paz entre os protagonistas de 1914, revoluções, revoltas, expansões, genocídios e novos pontos de tensão atravessaram o território europeu. Além disso houve em 1917 a Revolução Russa seguida da instauração do Estado Soviético com uma violenta guerra civil. Nos anos 30 houve a ascensão do fascismo na Itália e sua guerra imperialista na Etiópia, a ascensão dos EUA como potência militar e econômica, a quebra da bolsa de valores de Nova York (1929), a ascensão do partido nazista ao poder na Alemanha e a criação do Eixo. Todos estes fatores aqui rapidamente mencionados formam, de certa maneira, um novo palco nos quais os mesmos atores entrarão em cena.

Se os contemporâneos e sobreviventes do Primeiro Grande conflito (aqueles que não sofreram traumas psicológicos) acharam que haviam

\footnotetext{
${ }^{4}$ Tradução livre: Nova Objetividade - movimento artístico alemão surgido na década de 1920 como um desafio ao Expressionismo.

${ }^{5} \mathrm{O}$ quadro pode ser encontrado no site do Museum of Modern Art: $\langle$ http://www.moma.org/collection/browse_results.php?object_id=63261 >, acessado em 05/06/2015.
} 
visto de tudo, a Segunda Guerra, sem sombra de dúvidas, os fez mudar de ideia. A própria dinâmica do conflito é mais rápida, incluindo o famoso plano alemão Blitzkrieg, que significa guerra relâmpago. Porém, assim como a Primeira Guerra, ela não foi rápida e custou milhões de vidas e centenas de cidades destruídas. A título de comparação: enquanto a guerra franco-prussiana (1870-1871) matou por volta de $170 \mathrm{mil}$ vítimas, a Primeira e a Segunda ceifam 20 milhões e 70 milhões, respectivamente, sendo sua maioria civis e russos. Alguns historiadores consideram as duas grandes guerras como uma só, e, tomando essa linha de raciocínio, notamos que só na primeira metade do século $\mathrm{XX}, 90 \mathrm{mi}$ lhões de pessoas sucumbiram perante os conflitos, isso em números 'oficiais'.

Ao abordar o tema da Segunda Guerra podemos focar em diversos - se não infinitos - temas, porém gostaria de abordar aqui a questão do tempo e introduzir um novo elemento que, apesar de estar presente já ná Primeira Guerra toma grandes proporções na Segunda: a presença de fotógrafos e de jornalistas. A máquina fotográfica passa a fazer parte do cotidiano deste conflito armado. Inclusive os alemães passaram a contar com um fotógrafo para cada esquadrão, o que reforça a importância da relação entre guerra e imagem. $\mathrm{O}$ ato de tirar uma foto está intimamente ligado a dois fatores: 1) de documentar e 2) de noticiar, de conseguir a primeira página dos jornais. Temos assim o surgimento de uma nova profissão: o repórter de guerra que, ao invés de apontar uma arma, aponta sua câmera. 
Walter Benjamin (1892 - 1940), filósofo alemão, captou criticamente muito bem esse período de grandes conflitos que aqui está sendo abordado. Sua crítica ao chamado "progresso" é comprovada pelo próprio período que viveu. Ele não vê em todas as inovações tecnológicas apenas seu lado positivo de modo que estaríamos progredindo, mas chama atenção para o lado destrutivo da imensa racionalidade - ou a racionalidade do extremo - no qual o homem se encontrava (e ainda hoje se encontra?). É interessante notar que tudo o que se passa nos fronts é noticiado em jornais a partir da tecnologia, trazendo o cotidiano da guerra em imagens para os civis.

O advento da guerra nuclear em 1945 comprova sua descrença no progresso. O que pode ser usado para gerar energia e proporcionar um outro grande passo da ciência acaba por explodir duas cidades japonesas - Hiroshima e Nagasaki - e leva milhares de pessoas à morte e ao enorme perigo da radiação. Novamente muitas dessas cenas foram fotografadas e, especialmente, filmadas.

Com o fim da Segunda Guerra (1945) um novo cenário mundial se iniciou. Marcado por conflitos indiretos no âmbito econômico e cultural, a Guerra Fria acabou por dividir o planeta em, basicamente, dois grandes blocos: o bloco capitalista, tendo os EUA como principal agente, e o bloco comunista, liderado pela União das Repúblicas Soviéticas Socialistas (URSS). É neste momento, datado entre 1945 e 1989 (explosão das bombas atômicas - queda do muro de Berlim), que uma grande quantidade de filmes com imensa carga ideológica voltada ao anticomunismo/bolchevismo foram produzidos e exportados para os quatro 
cantos do mundo, principalmente para a América Latina e para as outras nações de 'Terceiro Mundo'/em desenvolvimento. Dirigidos por diretores norte-americanos - e com incentivo de Holywood - eles fazem parte do que podemos chamar de 'soft power' americano: são filmes voltados às massas, que de certa maneira buscam passar a propaganda ideológica alinhada a da Casa Branca.

Dessa maneira o presentismo se faz não somente no imaginário e na relação com o tempo, mas também em suas expressões culturais tanto de lazer como de crítica e questionamento.

Hartog define o tempo como algo que, perante o presentismo, se torna vendável: "tomado no tempo do consumo, também o tempo se torna um objeto de consumo" (Hartog, 2014: 160). Ele define o consumo de massa como "uma nova economia e "identidade do eu" (Hartog, 2014: 162). Já Svecenko aborda a cultura presentista também como um fenômeno de massa, algo que, aliada ao sistema capitalista (consumo) e a tendência mundial de globalização (1970 em diante), é alienadora e potencialmente homogenizadora. Dessa maneira a cultura passa a ser rentável, vendável, a preços internacionais de mercado. Em outras palavras, a cultura presentista busca criar um discurso único e onipresente perante seus consumidores.

"Essas distorções que a mentalidade do presentismo imprimiu nas esferas da política e das empresas foram ademais potencializadas por dois outros fatores que a transporiam também para os âmbitos da cultura, do comportamento e dos valores definidores do status social. Esses fatores foram a publicidade e o consumismo, que, fortalecidos pela desregulamentação dos mercados, pela revolução das comunicações e pela concentração de renda, se 
tornam a ideologia por excelência das sociedades neoliberais e o estofo de ilusões que veio a preencher o vazio do "pensamento único" (Sevcenko, 2001: 47).

Porém, não são todos os filmes ou diretores norte-americanos que atuaram/atuam em Hollywood que compactuam com a disseminação da carga ideológica do consumismo selvagem. Um desses diretores foi Stanley Kubrick (1928 - 1999) que entre diversos filmes com diferentes temáticas produziu trabalhos cinematográficos com um grande apelo/cunho anti-militar e anti-guerra. Destes trabalhos devemos citar Paths of Glory (Glória Feita de Sangue, 1957), Dr.Strangelove or: how I learned to stop worrying and love the bomb (Dr. Fantástico, 1964) e Full Metal Jacket (Nascido Para Matar, 1987). Os três filmes são considerados, conceitualmente, parte da 'Trilogia anti-guerra' do diretor.

A própria relação entre guerra e cinema, uma das discussões levantadas pelo presente artigo, é muito bem desenvolvida por Paul Virilio $^{6}$. Ele defende a ideia de que ambos, cinema e guerra, se desenvolveram juntos através da tecnologia: câmeras e instrumentos de percepção ocular foram desenvolvidas afim de obter vantagem tática sobre o inimigo ao mesmo tempo que foram usadas para registrar posições estratégicas e para fins propagandísticos:

“A guerra não pode jamais ser separada do espetáculo mágico, porque sua principal finalidade é justamente a produção deste espetáculo: abater o adversário é menos capturá-lo do que cativá-lo, é infligir-lhes, antes da morte, o pavor da morte" (Virilio, 2005: 24).

${ }^{6}$ VIRILIO, Paul. Guerra e cinema: logística da percepção. São Paulo: Boitempo, 2005. 
Esta lógica nos proporciona uma visão aparentemente estranha ao horror que um conflito armado produz, porém ela não deixa de ser verdadeira ao ponto que, de fato, a guerra é um espetáculo tanto quanto o cinema o é. Outro ponto que necessita destaque é a relação do presentismo com as produções cinematográficas. Ao tirar uma foto ou realizar uma filmagem o sujeito ativo desta ação (aquele que a realiza) está perpetuando um momento instantâneo - como uma risada ou uma paisagem - afim de guardá-lo (preservá-lo) para um momento futuro. De fato, este tipo de captura, quando usada para criar um conhecimento histórico, pode ser problemática ao ponto de que os fatos que a sucedem podem influenciar em seu entendimento, modificando completamente a percepção sobre a foto ou a filmagem. Nesta perspectiva podemos enquadrar diversos filmes (narrativas) que são produzindos durante ou logo após algum acontecimento. Alguns como Germania anno zero ${ }^{7}$, La battaglia di Algeri $^{8}$ ou Full Metal Jacket conseguem com sucesso tratar sobre temas latentes e contemporâneos à sua produção, o que nos indicia que ao mesmo tempo que estão construindo uma narrativa, um discurso sobre um acontecimento, estão discutindo o tempo imediato.

Lançado em junho de 1987, na reta final da Guerra Fria (1945 1989) e doze anos após o término da Guerra do Vietnã (1955 - 1975), o filme Full Metal Jacket (Nascidos para matar, 1987) procura demonstrar a transformação que um jovem norte-americano, Joker, sofre durante o período que participa como fuzileiro da Guerra do Vietnã. O longa

\footnotetext{
${ }^{7}$ Trad.: Alemanha ano zero; Produzido por Roberto Rossellini, 1948.

${ }^{8}$ Trad.: A Batalha de Argel; Produzido por Gillo Pontecorvo, 1966.
} 
foi dirigido pelo aclamado diretor norte-americano Stanley Kubrick (1928-1999) e assume uma postura contrária à guerra em diversas cenas sutis e algumas extremamente violentas. Ele é, como toda produção cultural/intelectual/de entretenimento, fruto de seu tempo, uma crítica ao seu momento contemporâneo (Guerra Fria) e portanto fruto do presentismo. Podemos até pensar em uma auto-crítica do presentismo expressada pelo cinema.

O filme é dinâmico, bem estruturado e procura captar momentos de sentimento que tanto vítimas como atuantes no conflito compartilharam. Ele, de fato, procura retratar de uma maneira bastante crítica aspectos de tensão, de combate, de ironia e de questionamentos que os envolvidos passaram. É possível até afirmar que o filme inteiro é composto apenas por conflitos: do campo de treinamento (bootcamp) à caminhada dos soldados já no final do longa, nenhuma cena memorável possui como foco um diálogo amistoso ou amigável. Os personagens não são vistos em suas casas ou com suas famílias, talvez em um momento de despedida ou de comemoração como em Deer Hunter $^{9}$, mas são diretamente introduzidos em um ambiente hostil, porém ainda nos EUA.

Dividida em duas, a narrativa questiona a "perda ou não da humanidade [de Joker] no processo [desenvolver do conflito]" (Duncan, 2003: 175). A primeira parte se passa no campo de treinamento do exército americano (bootcamp), onde os recrutas passam por um árduo processo - físico e mental -no qual são ensinados a matar. Sua transforma-

\footnotetext{
${ }^{9}$ Longa de Michael Cimio realizado em 1978. Trata também sobre a Guerra do Vietnã.
} 
ção é tão grande que, de certa maneira, renascem como assassinos, como máquinas para matar. Um dos recrutas, Pyle, não aguenta o treinamento, enlouquece (ou é o único são que não se adapta?) e acaba por matar o instrutor e se matar. Isso nos leva à questão do 'choque de guerra', porém, nesse caso, ele acontece antes mesmo de Pyle experimentar o combate.

Já segunda metade do filme se desenvolve com as experiências que Joker, agora como soldado-jornalista, é obrigado a passar. Ele trabalha para o jornal do exército Star and Stripes "onde sua função é escrever propaganda e não a verdade" (Duncan, 2003: 175), o que já nos leva em direção ao presentismo: a propaganda como a alma do negócio, quer dizer, da guerra.

Uma das cenas mais memoráveis do filme acontece durante a $B a$ talha de Hué que foi uma das maiores e sangrentas batalhas da guerra: durou entre janeiro e março de 1968. Esta batalha é considerada como um dos marcos da mudança da opinião pública americana de favorável a contrária a permanência e envio de tropas ao Vietnã. No filme o comandante do esquadrão de Joker é morto por uma mina e o ataque americano acaba se desorganizando e se perdendo. Este ataque 'falho' pode ser visto também como a própria permanência dos EUA no Vietnã que, após ser fortemente criticada e já abalada, se desorganiza e é obrigado a recuar.

A última sequência de cenas do filme se passa com os marines perdidos discutindo sobre o que fariam pois não possuem ordem claras. Após uma discussão decidem adentrar um conjunto de prédios destruí- 
dos. O esquadrão decide mandar Eightball explorar um pouco a área, porém ele é surpreendido por um franco atirador e acaba sendo morto. Após ver seu colega atingido um médico vai tentar salvá-lo e também acaba baleado. Então todos decidem ir ao encontro do vietcongue e, Joker, ao se aproximar para matá-lo vê que é apenas uma menina e não consegue atirar. Todo seu treinamento foi em vão, "porque ainda tem inteligência e humanidade dentro de si" (Duncan, 2003: 175). A atiradora é então ferida por outro marine. Ela cai no chão e, sofrendo, pede para matarem-a. Joker é quem atira. Ele se torna um assassino não por ódio, mas por compaixão.

Joker acaba sendo, portanto, questionado e testado durante toda sua trajetória, como soldado e jornalista de guerra, perante dois lados, creio que presentes em todas as ações humanas, inclusive na guerra: a humanidade e a violência. É de extrema importância ressaltar aqui os dois símbolos que ele carrega consigo: um bottom com o símbolo da paz, no peito, e a frase 'Born to kill' ${ }^{10}$ no capacete. Coração e mente. $\mathrm{O}$ coração que procura a paz e o amor - o que nos leva até a pensar no simbolismo de junho de 1968 - e a mente treinada (lavada) para o ódio, para matar.

Duas cenas são de grande importância para a relação do tempo e da guerra com a História, é a partir delas que toda a discussão apresentada e embasada por Hartog e Sevcenko toma corpo. Ambas acontecem durante a ofensiva americana a Hué e três jornalistas de guerra assumem a dianteira do filme. Na primeira cena, eles passam filmando alguns

\footnotetext{
${ }^{10}$ Trad. Livre: Nascido para matar.
} 
tanques de guerra americanos atirando na cidade e os soldados escondidos atrás de escombros. O pelotão que está sendo filmado é o de Joker, todos brincam e fazem piadas para a câmera como se estivessem se divertindo mas podemos pensar também que fazem isso como uma maneira de aliviar a tensão do ataque. A segunda cena é composta por uma série de entrevistas feitas com os marines, na qual a câmera foca cada um deles, individualmente, enquanto respondem a perguntas feitas a eles, como se fosse um tipo de 'talk show'.

Cada soldado responde duas perguntas de sua maneira a partir de seu repertório de vida, uns questionam por qual liberdade estão lutando, ou que os vietnamitas não querem liberdade. Porém, atentemos à fala de Joker: "I wanted to see exotic Vietnam... the crown jewel of Southeast Asia. I wanted to meet interesting and stimulating people of an ancient culture... and kill them. I wanted to be the first kid on my block to get a confirmed kill!" "11. Esta fala, extremamente irônica, não resume somente o posicionamento do soldado Joker como também do filme. Uma outra fala, ainda na linha de raciocínio de Joker, que merece atenção é a do soldado Eightball: "Personally, I think, uh... they don't really want yo be involved in this war. You know, I mean... they sort of took away our freedom and gave it to the, to the gookers, you know. But they don't want it. They'd rather be alive than free, I guess. Poor dumb bas-

\footnotetext{
${ }^{11}$ Trad. Livre: "Eu queria ver o que há de exótico no Vietnã... a jóia da coroa do Sudeste Asiático. Eu queria encontrar pessoas interessantes e estimulantes de uma cultura anciã... e matá-las. Eu queria ser o primeiro garoto em meu bloco [bairro] a ter uma morte confirmada!"
} 
tards" ${ }^{\prime \prime}$. Notamos que ela está diretamente relacionada à ideia de 'liberdade'. Eightball questiona o direcionamento da guerra, dizendo que ela não passa de uma guerra pela liberdade dos vietnamitas do sul em relação aos vietcongues comunistas do norte, mas não entende qual o seu propósito de estar ali. Sua visão é, de certa maneira, limitada, crê que está lá para lutar pela liberdade dos outros e não a favor da política externa militarista dos EUA. Um outro ponto interessante é o nome que chama seu inimigo, gooker, um apelido conotativo que nos remete ao apelido dado aos japoneses durante a Segunda Guerra.

A guerra do Vietnã foi o primeiro conflito a ser transmitido ao vivo e em rede nacional nos EUA e isso se encaixa perfeitamente no conceito de presentismo relacionado à guerra e ao cinema. Diversos jornalistas de grandes companhias de comunicação americana se arriscaram no campo de batalha em busca de uma foto, uma imagem, e não atrás da vitória. Para eles (e através deles) a documentação do momento se torna prioridade. Prioridade esta fruto de seu tempo, do presente extendido: o presente documentado que se torna passado e instantâneamente preservado para o futuro. Em outras palavras temos duas inquietudes e características apresentadas: 1) a intenção de documentar este momento histórico (historização do presente) e 2) de transmitir instantaneamente (ou

\footnotetext{
${ }^{12}$ Trad. Livre: "Pessoalmente, acho que, uh ... eles realmente não gostariam de estar envolvidos nesta guerra. Você sabe, eu quero dizer ... eles meio que tiraram nossa liberdade e deram-na aos, aos gookers [nome denotativo dado aos combatentes vietcongues], você sabe. Mas eles não querem isso. Eles preferem ficar vivos do que serem livre, eu acho. Pobres bastardos burros".
} 
quase) imagens, sons e notícias aos EUA, que está do outro lado do globo.

Temos como exemplo de jornalista Peter Arnett (1934 -) que ficou mundialmente famoso após ganhar o prêmio Pulitzer, em 1966, por seu trabalho durante a Guerra do Vietnã. Sua atuação não foi apenas na escrita de artigos e textos, publicados pela Associated Press (AP), mas também como correspondente em diversas operações realizadas pelos marines, sendo a mais famosa (e trágica) a batalha pela Colina 875 (Hill 875). Uma foto extremamente famosa e chocante de Eddie Adams (1933 - 2004), outro jornalista da AP, chamada The Execution ${ }^{13}$ (tirada em 1968 durante a Ofensiva do Tet), flagra o momento exato em que o General Nguyen Ngoc Loan, do Vietnã do Sul, executa friamente o prisioneiro de guerra Nguyen Van Lem no meio de uma rua. Este momento também foi filmado por uma equipe de cinegrafistas e, mais tarde, foi passado nos noticiários do dia. Essa situação abre um novo tipo de discussão na qual a execução deste homem está diretamente relacionada com a barbárie que não somente a Guerra do Vietnã causou, mas como outros conflitos ainda causam. $\mathrm{O}$ fato de se tornar um documento instantaneamente implica na permanência daquele momento nos três tempos (passado, presente e futuro). Ainda que violenta e trágica, esta imagem e este som um fragmento de tempo imortalizado.

Esta ânsia por informação não está ligada somente ao noticiário, mas também às próprias demandas da população americana, ansiosa a saber cada detalhe da guerra - batalhas e, talvez, notícias sobre seus

${ }^{13}$ Trad. Livre: "A execução". 
familiares -, e da Casa Branca preocupada em fazer a propaganda do conflito, incentivá-lo. A fala de Joker acaba sendo uma incógnita em relação à sua transmissão e divulgação, ainda mais no exato momento da virada da opinião pública americana de 'a favor' para 'contra' a guerra.

A partir da análise sob viés presentista sobre o cinema e a guerra, em especial a cena dos jornalistas de guerra do Full Metal Jacket, o estudo visa reforçar a importância do estudo desta teoria de Hartog. A abordagem historiográfica a partir do tempo, portanto, complementa e traz um outro olhar para a (já clássica) relação História e Cinema.

\section{Bibliografia}

D’ANGELO, Martha. Arte política e educação em Walter Benjamin. São Paulo: Edições Loyola, 2006. P.11-21.

HARTOG, François. Regimes de historicidade: presentismo e experiências do tempo. Belo Horizonte: Autêntica Editora, 2014.

DUNCAN, Paul. Stanley Kubrick - filmografia completa. Lisboa: Taschen, 2003.

SEVCENKO, Nicolau. A corrida para o século XXI: no loop da montanha-russa. São Paulo: Companhia das Letras, 2001.

Orfeu exático na metrópole - São Paulo, sociedade e cultura nos frementes anos 20. São Paulo: Companhia das Letras, 1992. P. 153-201.

MUNHOZ, Sidney J. O pior dos fins. Revista de História da Bilioteca Nacional, Rio de Janeiro, ano 10, nº 116, p. 36-37, maio de 2015. 
Cadernos de Clio, Curitiba, v. 6, nº. 2, 2015

VIRILIO, Paul. Guerra e cinema: logística da percepção. São Paulo: Boitempo, 2005.

Recebido em: 09/06/2015 Aceito em: 14/10/2015 